\title{
Armas químicas - Agentes Neurotóxicos: toxicologia e desenvolvimento de novos tratamentos
}

\author{
Chemical weapons - \\ Neurotoxic chemical weapons: \\ toxicology and development of new treatments
}

Rev. Bras. Est. Def. v. 5, nº 2, jul./dez. 2018, p. 37-59

DOI: $10.26792 /$ RBED.v5n2.2018.75094

ISSN 2358-3932

FELIPE OPPENHEIMER TORRES

CAMILLA COLASSO

\section{INTRODUÇÃO}

A classe de agentes químicos neurotóxicos ou tóxico dos nervos é atualmente a classe mais tóxica dos agentes químicos de guerra. Descoberta acidentalmente no século XX, esta classe de agentes logo despertou o interesse dos militares alemães, devido ao seu grande poder letal.

Presente em quase todas as gerações de agentes químicos $\left(2^{\mathrm{a}}\right.$ geração - agentes químicos neurotóxicos da série "G" e "V"; $3^{\mathrm{a}}$ geração - agentes químicos neurotóxicos binários da série "G" e "V"; e 4. geração - agentes químicos neurotóxicos binários da série A, Novichok), esta classe desperta interesse não só nas Forças Militares mundiais, mas também, infelizmente, em grupos terroristas, uma vez que o custo para a produção desta classe de agente químico é relativamente baixo, se comparado ao custo do método convencional de guerra, baseado na utilização de explosivos.

Felipe Oppenheimer Torres - Graduado em Direito pela Universidade Cândido Mendes (2006), com pós-graduação em Segurança Pública pela Faculdade Barddal (2012). Concluiu o Curso de Formação de Oficiais na Academia de Polícia Militar da Trindade (PMSC) em 2013. Atualmente é Capitão lotado no Grupamento de Polícia de Choque da Polícia Militar de Santa Catarina. É especialista na área de Operações de Choque (PMRN), Patrulhamento Tático Motorizado (PMRN) e Operações Químicas (PMDF). Instrutor na Faculdade da Polícia Militar de Santa Catarina (FAPOM).

Camilla Colasso - Farmacêutica-Bioquímica e mestre em Toxicologia e Análises Toxicológicas pela USP. Experiência na área de Regulatório e Segurança Química e de Produto, Gestão de Risco Químico e Especialista na área de Defesa Química e Toxicológica pela empresa Chemical Risk. Responsável por ministrar Palestras e Cursos: Antiterrorismo no Rio de Janeiro, UNICAMP; UNESP; Oswaldo Cruz, GRAU, Tropa de Choque, Exército, Corpo de Bombeiros, CiaDefNBQR - Marinha do Brasil, entre outros. 
Existe uma estimativa de que o ataque realizado com armas convencionais gera um custo aproximado de US\$2.000,00 por $\mathrm{km}^{2}$. Já em um ataque com arma química da classe dos neurotóxicos este custo cairia para US\$ 600,00 por $\mathrm{km}^{2}$ (Silva et al. 2012).

Se comparado a um ataque convencional utilizando explosivos, é inegável que um ataque químico com agente neurotóxico atingiria um número muito maior de vítimas, principalmente em grandes centros urbanos, local onde as pessoas não estão utilizando equipamentos de proteção individual para se precaverem de uma eventual exposição. Assim, temos uma arma de destruição em massa muito mais eficiente com um custo bem menor, quando comparamos com as armas convencionais explosivas.

Esta classe de agentes químicos é dividida basicamente em três séries: agentes da série G (Tabun - GA, Sarin - GB, Soman - GD, etilSarin - GE e cicloSarin - GF), agentes da série V (VX e R-33) e agentes da série A (Novichok).

Os agentes da série $\mathrm{G}$ receberam esta letra como código pois o $\mathrm{G}$ provém de Germany (Alemanha), uma vez que foi este o país em que os agentes dessa série foram desenvolvidos. A segunda letra após o $\mathrm{G}$ diz respeito à sequência na qual estes compostos surgiram. No entanto, a nomenclatura GC não foi estabelecida, pois poderia se confundir com CG, referente ao fosgênio. Já os neurotóxicos da série $\mathrm{V}$ provêm da expressão venomous (venenoso), pois, pelo fato desta série de agente penetrar de uma forma rápida na pele, lembrava o veneno de cobra (Tucker 2006).

Considerado por todos os países a principal preocupação quando o assunto é guerra química, os neurotóxicos já causaram milhares de vítimas em todo o mundo. Em 1967, durante a guerra do Iêmen, o Egito foi acusado pela Arábia Saudita de ter utilizado agentes químicos da classe dos neurotóxicos. ${ }^{1,2}$ Já na década de 1980, durante a Guerra Irã-Iraque, o Iraque utilizou os agentes químicos neurotóxicos Tabun e Sarin. No mencionado conflito, durante uma investida contra a população civil curda da cidade de Halabja, o Iraque, utilizando-se do agente químico neurotóxico Sarin, ocasionou o maior número de baixas registrado até hoje em um único ataque, cerca de 5.000 vítimas (Tucker 2006; Ganesan, Raza, and Vijayaraghavan 2010).

O desenvolvimento, produção e estocagem de armas químicas por parte de diversas nações, e a sua utilização por parte de alguns países, fez com que o mundo se preocupasse em criar uma legislação internacional mais abrangente e rigorosa para coibir a utilização destas armas de destruição em massa, uma vez que, até os anos 1990, a única legislação que tratava deste tema era o Protocolo de Genebra, assinado em 1925, protocolo este que proibia somente a utilização de armas químicas, mas não vetava a produção, estocagem e desenvolvimento destas. 
Assim, após longos anos de debate, no dia 13 de janeiro de 1993, foi assinada a Convenção para Proibição de Armas Químicas (CPAQ), conhecida também como Convenção de Paris. Diferentemente da legislação antecessora (Protocolo de Genebra), a CPAQ abrangeu a restrição em relação às armas químicas, uma vez que, além de proibir a utilização deste tipo de arma, proíbe também o seu desenvolvimento, produção e armazenamento (Oppenheimer Torres 2018).

Apesar de ter sido assinada em 1993, a mencionada Convenção só entrou em vigor em 29 de abril de 1997, mesmo dia em que foi fundada a Organização para a Proibição de Armas Químicas (OPAQ). Com sede em Haia, esta organização tem a responsabilidade de fiscalizar e implementar a CPAQ. A OPAQ é uma organização internacional independente filiada à Organização das Nações Unidas (Oppenheimer Torres 2018).

Atualmente, quatro países não são signatários da CPAQ: Egito, Coreia do Norte, Sudão do Sul e Israel. Com a entrada em vigor da CPAQ, os países signatários que possuíam estoques de armas químicas foram obrigados a destruí-los. No entanto, infelizmente, alguns países que assinaram a referida Convenção continuam ainda produzindo e utilizando este tipo de arma de destruição em massa.

Em 2018, a Síria foi acusada por diversas vezes de ter utilizado armas químicas na guerra civil que assola o seu território. Entre os agentes químicos usados, foi constatada a utilização do Sarin. Ainda em 2018, a Rússia foi acusada de ter utilizado o agente químico Novichok, em território inglês, na tentativa de assassinato do ex-espião russo Sergei Skripal e sua filha. Apesar destes recentes casos de utilização de agentes neurotóxicos por Estados constituídos, a maior preocupação para os países, sem dúvida, é a possibilidade de utilização destas substâncias extremamente letais por parte de organizações terroristas, como já ocorreu nos anos de 1990. Em 27 de junho de 1994, a seita japonesa Aum Shinrikyo, realizou um ataque com Sarin na cidade de Matsumoto, o qual matou sete pessoas. No ano seguinte, no dia 20 de março, novamente a mesma seita realizou um segundo ataque terrorista com Sarin, desta vez no metrô de Tóquio, matando treze pessoas. Nos dois ataques realizados pela seita, o número de vítimas só não foi maior porque o método de dispersão do agente químico utilizado era bastante precário e a pureza do agente químico era baixa (Tucker 2006). A combinação de ataques terroristas com armas de destruição em massa, como os agentes químicos, por exemplo, fez surgir uma forma moderna de terrorismo denominada de ultra terrorismo (Pitschmann 2014). O interesse por parte dos terroristas neste tipo de arma ocorre pelo fato de ser uma substância extremamente barata, acessível e letal, uma vez que, para ocasionar a morte, basta uma concentração muito baixa, conforme pode ser verificado na Tabela 1. 


\section{Tabela 1}

Concentrações letais dos principais agentes químicos neurotóxicos da série "G" e "V"

\begin{tabular}{|c|c|c|}
\hline Agente químico & LCt5o $\left(\mathbf{m g} \mathbf{x} \mathbf{~ m i n} / \mathbf{m}^{\mathbf{3}}\right)$ & LD50 $(\mathbf{m g} / \mathbf{7 0 k g})$ \\
\hline Tabun $(\mathrm{GA})$ & 70 & 1.500 \\
\hline Sarin $(\mathrm{GB})$ & 35 & 1.700 \\
\hline Soman $(\mathrm{GD})$ & 35 & 350 \\
\hline VX & 15 & 5 \\
\hline
\end{tabular}

Fonte: Adaptado Pitschmann 2014.

Ademais, os avanços tecnológicos, a acessibilidade causada pelas informações contidas na internet, a globalização e a corrupção existente em alguns países que detêm estoques destas armas químicas, facilitam o acesso a estas armas de destruição em massa por parte dos terroristas.

Assim, o presente trabalho visa abordar os principais agentes químicos neurotóxicos existentes, abordando a parte histórica, mecanismos de ação no organismo, tratamentos existentes e tratamentos futuros que muito poderão facilitar em uma eventual exposição a este agressivo químico.

\section{HISTÓRICO}

O primeiro relato da utilização de um agente neurotóxico remonta aos anos de 1850, na África, mais precisamente no Gâmbia (atual Gana) e Serra Leoa. Naquela ocasião, o feijão de Calabar (Physostigma venenosum) era utilizado para determinar se um indivíduo era inocente ou culpado de praticar bruxaria. Se o acusado, ao ingerir um elixir composto por estes grãos, que eram antes triturados e depois misturados com água, vomitasse, expelindo aquela substância, seria considerado inocente, no entanto, se morresse após a ingestão, era considerado culpado (Sidell, Newmark, and Mcdonough 2008; Mors 2018).

O feijão de Calabar recebeu esse nome por ser abundante nas margens do rio Calabar, na Nigéria, e o mecanismo de ação deste no organismo humano ocorre da mesma forma que os agentes neurotóxicos desenvolvidos como armas químicas no século seguinte, ou seja, inibindo a enzima acetilcolinesterase (Mors 2018).

No entanto, foi durante o século XX que tal classe de agentes ficou muito conhecida em função de suas propriedades toxicológicas, tornando-se amplamente pesquisada e voltada para o emprego como arma química de destruição em massa. 
No dia 23 de dezembro de 1936, o químico alemão Gerhard Schrader, da I. G. Farben (aglomerado de indústrias químicas alemãs), ao pesquisar a utilização de componentes organofosforados para criar um pesticida, acidentalmente isolou o composto químico etil $N, N$-dimethylphosphoramidocyanidate $\left(\mathrm{C}_{5} \mathrm{H}_{11} \mathrm{~N}_{2} \mathrm{O}_{2} \mathrm{P}\right)$ e desenvolveu uma substância extremamente nociva aos seres humanos (Salem, Ternay, and Smart 2008).

Curiosamente, os primeiros a testar este novo agente químico foram os seus próprios criadores, Schrader e o seu assistente, que acidentalmente deixaram cair uma pequena quantidade na bancada do laboratório, o que causou a eles contração das pupilas (miose) e dificuldade em respirar (Salem, Ternay, and Smart 2008).

Logo o cientista percebeu que tal substância não poderia ser utilizada como pesticida, devido ao seu elevado poder tóxico. Assim, seguindo uma determinação do Partido Nazista, que havia emitido um decreto em 1935, estabelecendo que toda invenção que pudesse despertar um interesse militar deveria ser informada ao Ministério da Guerra alemão, Schrader reportou sua descoberta.

Inicialmente, esta substância recebeu o nome de Le-100, e posteriormente de Trilon-83. Mais tarde, ela receberia o nome de Tabun (Salem, Ternay, and Smart 2008).

Dois anos após o desenvolvimento do Tabun, em 1938, Schrader desenvolveu um segundo composto organofosforado, dez vezes mais tóxico que o Tabun, o isopropyl methylphosphonofluoridate $\left(\mathrm{C}_{4} \mathrm{H}_{10} \mathrm{FO}_{2} \mathrm{P}\right)$. Inicialmente chamado de T-144 ou Trilon-46, esta substância mais tarde ficaria conhecida como Sarin (GB), que recebeu este nome em homenagem aos seus criadores (Schrader, Ambros, Rudriger e van der Linde) (Sidell, Newmark, and Mcdonough 2008; Salem, Ternay, and Smart 2008).

O Tabun começou a ser fabricado pela Alemanha para ser estocado e possivelmente utilizado como arma química em 1940, na cidade de Elberfeld, Alemanha, e posteriormente a produção foi transferida para Dyhernfurth, Polônia (Salem, Ternay, and Smart 2008).

Durante a Segunda Guerra Mundial, a pesquisa por novas armas químicas continuou a ser desenvolvida, sendo descoberto em 1944, pelo químico alemão Richard Kuhn, o Soman (pinacolyl methyl phosphonofluoridate) $\left(\mathrm{C}_{7} \mathrm{H}_{16} \mathrm{FO}_{2} \mathrm{P}\right)(\mathrm{GD})$ (Salem, Ternay, and Smart 2008). Este agente químico é mais tóxico que o Tabun e o Sarin, e considerado um dos mais perigosos e letais agentes neurotóxicos existentes atualmente, uma vez que ocasiona o aging $^{3}$ das enzimas acetilcolinesterase de forma muito rápida. Uma vez ocasionado este aging, não é mais possível reverter e voltar a produção da acetilcolinesterase por meio da administração de oxima (Mcdonough and Romano Jr. 2008). 
Durante a Segunda Guerra Mundial, a Alemanha ainda desenvolveu dois outros agentes neurotóxicos, etillSarin $\left(\mathrm{C}_{5} \mathrm{H}_{12} \mathrm{FO}_{2} \mathrm{P}\right)(\mathrm{GE})$ e cicloSarin $\left(\mathrm{C}_{7} \mathrm{H}_{14} \mathrm{FO}_{2} \mathrm{P}\right)(\mathrm{GF})$; no entanto, não foram considerados adequados para serem utilizados como armas químicas.

Os Estados Unidos da América e a Inglaterra, ao longo da Segunda Guerra Mundial, também realizaram diversas pesquisas para desenvolver os agentes neurotóxicos. O mais conhecido foi o DFP (diisopropyl flurorophosphate). Entretanto, este agente químico era muito menos tóxico que os agentes da série $G$ e seus efeitos fisiológicos afetavam os olhos, semelhante aos efeitos dos lacrimogêneos. Ademais, para se atingir uma concentração letal deste agente, era necessária uma quantidade muito alta, o que dificultava o seu emprego como uma arma química letal (Nerve 2018).

Com o fim da Segunda Guerra Mundial, os países Aliados começaram a dar uma importância maior na pesquisa sobre os agentes neurotóxicos.

Em 1952, na Inglaterra, foi sintetizado pela primeira vez o agente VX (O-ethyl S-[2-(diisopropylamino)ethyl] methylphosphonothiolate) $\left(\mathrm{C}_{11} \mathrm{H}_{26} \mathrm{NO}_{2} \mathrm{PS}\right)$ pelo químico Ranajit Ghosh, que pesquisava um novo tipo de pesticida para substituir o DDT. Ao perceber a grande toxidade desta substância, esta foi entregue para o Centro de Pesquisas de Armas Químicas e Biológicas em Porton Down (Salem, Ternay, and Smart 2008).

Como os britânicos já estavam comprometidos com a produção de Tabun e Sarin, eles entregaram tal descoberta aos Estados Unidos da América e Canadá, para que estes dois países pudessem continuar desenvolvendo pesquisas sobre esta nova substância (Sidell, Newmark, and Mcdonough 2008).

No final dos anos de 1950, uma operação de espionagem russa obteve sucesso em adquirir a fórmula secreta do VX. Nos anos seguintes, a União Soviética desenvolveu um análogo do VX, chamado de R-33. Inicialmente pensava-se que o R-33 era uma réplica do VX; no entanto, estudos realizados anos depois demonstraram que o R-33 era mais letal e tinha chances menores de ser tratado que o VX, uma vez que o aging da acetilcolinesterase provocado pelo $\mathrm{R}-33$ era mais rápido que o provocado pelo $\mathrm{VX}$ (Tucker 2006).

Com o intuito de se manter na frente dos EUA durante a corrida armamentista, a União Soviética manteve um ativo programa de pesquisa e desenvolvimento de novos agentes químicos de guerra.

Em maio de 1971, o Comitê Central do Partido Comunista e o Conselho Soviético de Ministros aprovaram um novo programa para criar as armas químicas de $\mathbf{4}^{\mathbf{a}}$ geração, programa este denominado de Foliant, que era liderado pelo cientista Dr. Pyotr Petrovich Kirpichev (Tucker 2006). 
Com a aprovação deste programa, o Kremlin desejava criar uma nova classe de agente químico, mais tóxica, mais estável, mais persistente e mais fácil de ser produzida.

Em 1973, Kirpichev sintetizou um agente neurotóxico organofosforado que continha nitrogênio em sua fórmula, o qual inicialmente recebeu o nome de K-8, e posteriormente de A-230 (Tucker 2006).

Durante os anos de 1970 os cientistas continuaram a desenvolver pesquisas em cima desta nova classe de agentes neurotóxicos, surgindo diversas variações do A-230. Entretanto, os mais promissores foram o A-230 e A-232 (Tucker 2006).

A estrutura molecular do A-232 era muito parecida com a do A-230; no entanto, havia uma importante diferença, o A-230 era um fosfonato que continha uma ligação direta de carbono-fósforo, enquanto que o A-232 era um fosfato, ou seja, os átomos de carbono e de fósforo estavam ligados por um átomo de oxigênio (Tucker 2006).

Este fato era de extrema importância, pois, pelo fato dos precursores do A-232, bem como os produtos de sua quebra, não possuírem uma ligação carbono-fósforo, a sua produção não seria identificada pelos inspetores de arma química, tampouco por espiões estrangeiros, uma vez que esta ligação de carbono-fósforo que é a marca registrada dos agentes neurotóxicos como Sarin, Soman e o VX (Tucker 2006).

Com esta nova descoberta, os cientistas receberam um grande incentivo por parte do governo soviético, o que fez com que as pesquisas sobre estes novos agentes pudessem avançar significativamente. A série "A" é considerada de 5 a 8 vezes mais letal que o VX, uma vez que este agente químico passa rapidamente da corrente sanguínea para o sistema nervoso central através da penetração da barreira hematoencefálica. Assim como o Soman, esta nova classe consegue inativar a acetilcolinesterase de forma irreversível em poucos minutos (Tucker 2006).

No final dos anos 1980, o A-232 começou a ser desenvolvido para ser produzido no sistema binário de arma química. A esta versão binária do A-232 se deu o nome de Novichok-5, uma vez que a versão binária do agente químico R-33 recebeu o nome de Novichok (newcomers - o que na língua portuguesa significaria "recém-chegados"; entretanto, adotaremos o termo em inglês). Já em 1993, o professor Georgi Drozd descobriu uma nova fórmula, a qual foi denominada de Novichok-7, a qual tinha a volatilidade similar ao do Soman, porém dez vezes mais potente. (Tucker 2006).

O Novichok-5 tem dois componentes binários, um contendo fósforo e o outro nitrogênio, o que torna a produção ilícita dos seus componentes fácil de ser ocultada dos inspetores internacionais de armas, uma vez que 
os componentes precursores do Novichok-5 são relativamente não tóxicos e são utilizados na fabricação de pesticidas ou fertilizantes (Tucker 2006).

A partir da década de 1980 os agentes químicos neurotóxicos entrariam em uma nova fase, a fase binária, dando origem a um novo tipo de arma química, as armas químicas binárias.

\section{ARMA QUÍMICA BINÁRIA}

Após um incidente ocorrido em um teste militar com o agente químico VX, em 1968, no estado de Utah, que ocasionou a morte de mais de 4.000 ovelhas, e o vazamento de Sarin de uma bomba da Marinha americana, armazenada na ilha de Okinawa, em 1969, que resultou no ferimento de 23 militares e 1 civil, o Presidente Richard Nixon determinou, em 1969, a suspensão da produção americana de agentes químicos de guerra em sua forma unitária (Salem, Ternay, and Smart 2008).

Contudo, a corrida armamentista, incluindo as armas químicas, gerada pela Guerra Fria, e o fato de diversos países durante os anos de 1970 e 1980 continuarem a empregar armas químicas em alguns conflitos, levou os EUA a voltarem a produzir os agentes químicos neurotóxicos em 1987, para uma eventual retaliação caso fossem atacados com armas químicas.

Entretanto, os EUA começaram a produzir os agentes químicos neurotóxicos na forma binária. Por exemplo, o Sarin foi dividido em dois precursores químicos menos letais (difluoreto de metilfosfonilo - DF, e uma substância denominada de OPA - álcool isopropílico e isopropilamina), precursores estes que eram armazenados em recipientes separados (Tucker 2006).

Desta forma, evitava-se a exposição indesejada na eventual hipótese de um vazamento acidental, um ataque terrorista ou ataque de uma nação inimiga nos locais que armazenavam os agentes químicos.

As armas químicas binárias funcionam da seguinte forma: as substâncias precursoras são armazenadas de forma separada em recipientes metálicos diferentes. Instantes antes do projétil ser disparado, esses dois recipientes são introduzidos no corpo do projétil. Quando o projétil é disparado, a força de empuxo exercida no projétil faz com que uma fina membrana de polímero e aço, existente entre esses dois recipientes, se rompa, permitindo que os dois precursores químicos, em 4 segundos, se misturem, devido ao movimento giratório do projétil durante o seu deslocamento, formando o agente químico neurotóxico, que será dispersado no ambiente na forma de aerossol quando o projétil atinge o seu alvo (Tucker 2006). 
No entanto, as armas químicas binárias possuem algumas desvantagens (Tucker, 2006):

- O alvo deve estar a uma determinada distância do local do disparo, uma vez que, se isto não for observado, as substâncias precursoras não conseguirão se misturar de forma eficaz e, consequentemente, o agente químico não conseguirá ser formado durante o voo do projétil;

- Pelo fato de o agente químico neurotóxico ser formado durante o deslocamento do projétil, por meio da mistura de duas substancias precursoras, isto faz com que o projétil, ao atingir o seu destino, tenha uma subutilização do agente químico, pois pode ocorrer que durante o deslocamento as duas substancias precursoras não tenham conseguido se misturar por completo, deixando, assim, uma porcentagem das substancias subutilizadas, dispersando, consequentemente, menos agente químico neurotóxico do que o desejado;

- A utilização do DF tem a desvantagem de gerar fluoreto de hidrogênio (HF), substância química que exala odor, diferente do Sarin, que é inodoro. Desta forma, as tropas inimigas perceberiam a aproximação da nuvem de agente químico neurotóxico.

O desenvolvimento desta nova geração de armas químicas (binárias) fez com que a opinião pública, pelo menos durante um tempo, aceitasse mais facilmente o seu armazenamento para uma eventual retaliação a um ataque químico. No entanto, o seu poder devastador sobre os seres vivos continuou assombrando as nações mundiais.

\section{PROPRIEDADES FÍSICO-QUÍMICAS DOS AGENTES NEUROTÓXICOS}

Os neurotóxicos da série $G$ são líquidos viscosos com variável volatilidade - densidade de vapor $(\operatorname{ar}=1)$ entre 4,86 e 6,33 - com odor fraco (levemente de fruta ou apimentado ou parecido com cânfora). O agente VX é um líquido de coloração âmbar com densidade de vapor $(a r=1)$ de 9,2 e sem odor. Assim, os vapores dos agentes neurotóxicos possuem pouca ou nenhuma propriedade de aviso olfativo (Watson et al. 2009).

A pressão de vapor e a toxicidade aguda desses agentes são elevadas para os vapores serem rapidamente letais. Dentre a série G, o agente GB (Sarin) é considerado o vapor com maior perigo (ordem de vapor de perigo aproximado GB $>$ GD $>$ GF $>$ GA). $\mathrm{O}$ agente $\mathrm{VX}$ foi formulado para possuir uma baixa volatilidade, o VX é aproximadamente 2.000 vezes menos volátil que o agente GB. Como consequência, o agente VX é considerado um composto militar persistente, com potencial de risco de contato ou que 
gera concentrações de vapor tóxico ou "gases tóxicos" durante um período de dias após a aplicação da superfície, especialmente sob condições de clima frio ou quando quantidades de liberação em massa do agente líquido estão envolvidas. Embora não sejam facilmente voláteis, os vapores VX (se permitido acumular) são, no entanto, considerados mais intensamente potentes do que os do agente $\mathrm{GB}$ ou dos outros agentes da série $\mathrm{G}$ (Watson et al. 2009).

Devido à volatilidade dos agentes neurotóxicos da série $G$, a via de exposição mais relevante para esses agentes é através da via inalatória por meio da absorção sistêmica dos vapores, além da exposição ao vapor dos neurotóxicos via ocular e pelo trato respiratório superior. $\mathrm{O}$ agente VX apresenta uma característica um pouco diferente - apresenta risco de exposição pela via cutânea quando comparado com os agentes neurotóxicos da série $\mathrm{G}$, e apresenta também exposição pela via inalatória através de vapores em ambientes com temperaturas elevadas (ex.: $>40^{\circ} \mathrm{C}$ ) (Watson et al. 2009).

\section{MECANISMO DE AÇÃO DOS AGENTES NEUROTÓXICOS}

Os agentes neurotóxicos, tanto da série G como os da série V, são agentes chamados anticolinesterásicos e induzem ao acúmulo do neurotransmissor acetilcolina (ACh) tanto nas sinapses neurais como nas junções neuromusculares pela fosforilação da serina localizada no sítio ativo da enzima acetilcolinesterase (AchE) (Sidell et al. 2008; Watson et al. 2009).

A depender da via de exposição e da quantidade absorvida dos agentes neurotóxicos, tanto o sistema nervoso periférico (SNP) como o sistema nervoso central (SNC), através dos receptores muscarínicos e/ou nicotínicos, são afetados. Pode ocorrer também a interação com outras esterases, e observa-se a ocorrência de efeitos direitos para o SNC (Sidell et al. 2008).

A exposição aguda aos neurotóxicos pode resultar em secreção brônquica excessiva, secreção salivar excessiva, ocular, além de secreção intestinal, fasciculações e espasmos musculares, hipermotilidade intestinal, bradicardia, sudorese, miose, broncoespasmo, bradicardia, fraqueza muscular, paralisia, perda de consciência, convulsões, depressão do centro respiratório e morte (Watson et al. 2009).

Os efeitos mínimos observados a baixas concentrações de vapor incluem miose, aperto no peito, rinorreia e dispneia. A contração pupilar resulta em vários graus de miose (medidas do diâmetro da pupila), e é consequência da inibição local da atividade da AchE ocular com a contração do esfíncter pupilar. 
$\mathrm{O}$ agente GD apresenta um aging muito rápido quando ligado à acetilcolinesterase no glóbulo vermelho (RBC-ChE), com tempo de meia vi$\mathrm{da}-\mathrm{T}_{1 / 2}$ (tempo necessário para $50 \%$ da enzima se tornar resistente à reativação) de 1,3 minutos (Watson et al. 2009).

$\mathrm{O}$ agente neurotóxico GA apresenta o tempo de meia-vida (ligação da acetilcolinesterase no glóbulo vermelho) RBC-ChE de 46h, e o tempo de meia-vida do GB com RBC-ChE é de 5h. O complexo formado entre agente $\mathrm{VX}$ e a acetilcolinesterase no glóbulo vermelho (RBC-ChE) não apresenta envelhecimento significativo (tempo de meia-vida de aproximadamente 48h) (Watson et. al. 2009).

\section{Efeitos diretos no sistema nervoso}

Embora os neurotóxicos exerçam efeitos tóxicos tanto no SNC e SNP indiretamente por inibição da AchE, esses compostos neurotóxicos também podem afetar o impulso da transmissão nervosa por mecanismos adicionais nas junções neuromusculares e nos sítios receptores de neurotransmissores no SNC (Sidell et al. 2008).

Estudos conduzidos por Rao et al. (1987) relataram que a exposição ao VX provocou aumento da liberação de ACh nas junções neuromusculares em sapos, através da interação com receptor nicotínico. Estudos conduzidos por Aas et al. (1987) relataram alterações em receptores muscarínicos em brônquios e tecidos pulmonares de ratos por exposição subaguda ao agente GD. No SNC, agentes neurotóxicos podem atuar diretamente nos receptores muscarínicos, nicotínicos e de glutamato de maneiras não relacionadas à inibição da acetilcolinesterase (Watson et al. 2009).

Estudo conduzido por Lallement et al. (1991a, b) sugeriu que anteriormente a superestimulação dos receptores glutamatérgicos induzidos pelo agente GB contribuiu para a manutenção das convulsões. Embora esses efeitos eletrofisiológicos indiquem que os agentes neurotóxicos podem atuar diretamente no SNC não relacionado à inibição da acetilcolinesterase, com os dados obtidos não é possível se determinar uma dose para letalidade e nem mesmo uma comparação qualitativa/quantitativa que sejam relevantes para o efeito adverso.

\section{Ligação com colinesterases sanguíneas.}

\section{A atividade da acetilcolinesterase do glóbulo vermelho (eritrocitária)}

A atividade da colinesterase dos glóbulos vermelhos (RBC-ChE), também chamada de acetilcolinesterase eritrocitária, bem como a da acetilcolinesterase plasmática (pseudocolinesterase — também conhecida como 
colinesterase sérica, butirilcolinesterase), são empregadas para monitorar a exposição e recuperação de agente neurotóxicos e praguicidas organafosforados (Sidell et al. 2008).

Existem algumas evidências históricas de que o RBC-ChE pode ser tão sensível quanto a ChE cerebral aos efeitos anticolinesterásicos dos agentes neurotóxicos. Estudos conduzidos por Grob e Harvey (1958) relataram que a concentração in vitro produz $50 \%$ de depressão da atividade cerebral - CHE e RBC-CHE são equivalentes no caso de agentes GA $\left(1,5 \times 10^{-8} \mathrm{~mol} / \mathrm{L}\right)$, e comparável no caso do $\mathrm{GB}\left(3,0 \times 10^{-9} \times 3,3 \times 10^{-9} \mathrm{~mol} / \mathrm{L}\right)$. Estudos conduzidos por Jimmerson et al. (1989) com animais in vivo, discordam: informam que o que é ainda apoiado pelo fato de que a atividade sanguínea da ChE nem sempre pode ser correlacionada com a exposição ou com sinais e sintomas de toxicidade. Tal fato também foi observado durante o tratamento clínico das vítimas do ataque terrorista com GB (sarin) em Matsumoto, no Japão, em 1995 (Sidell et al. 2008).

Geralmente, considera-se que os efeitos sistêmicos em seres humanos após exposições agudas aos neurotóxicos são prováveis quando o nível de hemácias é inibido de 75 a 80\% (por exemplo, para 20 a 25\% dos níveis normais de atividade). Entretanto, está bem definido que os sinais e sintomas apresentados em indivíduos com exposição aos olhos e ao nariz (por ex.: miose e rinorreia) podem ocorrer na ausência de qualquer alteração mensurável da atividade basal da ChE no sangue, após a exposição aos vapores ou aerossol dos neurotóxicos. Tais efeitos locais são atribuídos pela ação direta desses agentes nos tecidos oculares e no trato respiratório superior. Quando ocorre exposição sistêmica (por exemplo, diferente da exposição ocular e nasal direta), a miose e a rinorréia geralmente não são observadas como os primeiros efeitos perceptíveis (Watson et al. 2009).

\section{Ligação com outras enzimas}

Os agentes neurotóxicos também podem interagir com enzimas de desintoxicação, como as carboxilesterases (CarbE) e A-esterases (por exemplo, aril-esterase e paraoxonase), e o grau dessa interação pode alterar a magnitude e a extensão da cascata tóxica, após a inibição da AchE, bem como as características específicas de cada espécie. A reativação espontânea observada da CarbE plasmática inibida por pequenas quantidades em roedores indica que o aging não ocorre para o complexo CarbE do plasma-GD (em contraste com o observado para GD e RBC-ChE) e sugere ainda que a CarbE plasmática endógena pode ser um principal "limpador" funcional para o agente GD (Watson et al. 2009). 


\section{Toxicidade}

Os efeitos anticolinesterásicos da exposição aos agentes neurotóxicos podem ser caracterizados como muscarínico, nicotínico ou ao SNC (Sidell et al. 2008).

Os efeitos muscarínicos ocorrem no músculo liso que envolve as vias aéreas do pulmão e o trato gastrointestinal; no músculo ciliar do olho (responsável por controlar o tamanho da íris); e nas glândulas salivares e sudoríparas (Tucker 2006). Dependendo da quantidade absorvida, podem aparecer os seguintes sintomas: congestão conjuntival, miose, espasmo ciliar, aumento da secreção brônquica, broncoconstrição, anorexia, êmese, cólicas abdominais, sudorese, diarreia, salivação, bradicardia e hipotensão (Watson et al. 2009).

Os efeitos nicotínicos são aqueles que ocorrem nos sistemas somático (esquelético/motor) e simpático, e podem ser expressos como fasciculações musculares e paralisia (Watson et al. 2009).

Os efeitos do SNC podem manifestar-se como confusão, perda de reflexo, ansiedade, fala arrastada, irritabilidade, esquecimento, depressão, julgamento prejudicado, fadiga, insônia, depressão do controle respiratório central e morte.

Os efeitos mínimos observados em baixas concentrações em seres humanos incluem miose, sensação de "aperto" no peito, rinorreia e dispneia (Sidell et al. 2008).

A Tabela 2 resume os principais efeitos dos agentes neurotóxicos em humanos. 


\section{Tabela 2}

\section{Efeitos dos agentes neurotóxicos em humanos}

\begin{tabular}{|c|c|}
\hline Órgãos e sistemas & Efeitos \\
\hline Olhos & $\begin{array}{l}\text { Miose (unilateral ou bilateral); hiperemia da conjuntiva; dor } \\
\text { ou ardor, visão escura ou turva }\end{array}$ \\
\hline Nariz & Rinorréia \\
\hline Boca & Salivação excessiva \\
\hline Trato pulmonar & $\begin{array}{l}\text { Broncoconstrição e secreção, tosse, queixas de aperto no peito, } \\
\text { falta de ar, sibilo, estertores }\end{array}$ \\
\hline Trato gastrointestinal & $\begin{array}{l}\text { Náusea, vomito, diarreia, aumento de secreção e motilidade, } \\
\text { câimbras abdominais e dor }\end{array}$ \\
\hline $\begin{array}{l}\text { Pele e glândulas } \\
\text { sudoríparas }\end{array}$ & Sudorese \\
\hline Muscular & $\begin{array}{l}\text { Fasciculações locais ou generalizadas; espasmos musculares; } \\
\text { fraqueza muscular }\end{array}$ \\
\hline Cardiovascular & $\begin{array}{l}\text { Diminuição ou aumento da frequência cardíaca, normalmente } \\
\text { aumento da pressão arterial }\end{array}$ \\
\hline $\begin{array}{l}\text { Sistema Nervoso } \\
\text { Central }\end{array}$ & $\begin{array}{l}\text { Efeitos agudos em exposição severa: perda de consciência, } \\
\text { convulsão, depressão do centro respiratório. } \\
\text { Efeitos agudos em exposição leve a moderadas ou efeitos } \\
\text { prolongados em qualquer exposição: esquecimento, } \\
\text { irritabilidade, dificuldade de raciocínio, tensão ou mal-estar, } \\
\text { depressão, insônia, dificuldade de expressão, compreensão } \\
\text { diminuída. }\end{array}$ \\
\hline
\end{tabular}

Fonte: Sidell et al. 2008.

\section{AVALIAÇÃO DE OUTROS POTENCIAIS EFEITOS}

Estudos realizados em animais por meio da exposição por vapor, ingestão e injeção aos neurotóxicos da série G e para o agente VX, não evidenciaram toxicidade reprodutiva ou no desenvolvimento em mamíferos (Sidell et al. 2008).

Foram obtidos dados referentes a mulheres entre 9 e 36 semanas de gestação que foram expostas a concentrações tóxicas do agente GB durante o ataque ocorrido no metrô de Tóquio e cujas crianças nasceram saudáveis (Watson et al. 2009).

Estudos conduzidos para avaliação do potencial mutagênico em mamíferos não evidenciaram que o GB e nem o VX apresentam potencial de provocar mutagenicidade. Entretanto, o agente GA apresenta fraco potencial mutagênico quando ensaios celulares são conduzidos (Watson et al. 2009). 
Resultados experimentais indicam que os agentes GB, GA e VX não possuem potencial carcinogênico (Watson et al. 2009).

Devido aos efeitos fisiológicos extremamente tóxicos causados nos seres humanos, a grande preocupação por parte dos países, quando o assunto é guerra química, é desenvolver um tratamento eficaz e rápido para ser ministrado para a população num eventual ataque químico com neurotóxicos. Além disso, paira ainda sobre os pesquisadores a responsabilidade e necessidade de desenvolver um pré-tratamento eficiente, principalmente para os militares que estão sujeitos a combater em ambientes contaminados por esta classe de agente químico.

\section{PRÉ-TRATAMENTOS}

Apesar de já haver um pós-tratamento específico para a contaminação com agentes neurotóxicos (atropina, oxima e diazepan), o desenvolvimento de pré-tratamentos é de suma importância, uma vez que, dependendo da concentração e de qual agente neurotóxico ocasionou a contaminação, o socorro médico deve ser realizado dentro de poucos minutos, sob pena do individuo contaminado vir a óbito.

Neste cenário, os pré-tratamentos são de fundamental importância. Atualmente existe o pré-tratamento com brometo de piridostigmina e a pesquisa para a criação de um novo tipo de pré-tratamento com butirilcolinesterase (bioscavengers — "biolimpadores").

\section{Brometo de piridostigmina}

A ideia de utilizar carbamatos no pré-tratamento que protege contra intoxicação provocada por organofosforados foi realizada pela primeira vez em 1956, por Koster, que demonstrou que gatos pré-tratados com uma pequena dose de eserina (fisiostigmina) sobreviveram a uma intoxicação causada por uma dose letal de DFP (Scott 2007).

$\mathrm{O}$ mecanismo de ação da piridostigmina como pré-tratamento ocorre da seguinte forma: o carbamato se liga a uma quantidade de enzimas acetilcolinesterase formando uma ligação estável e impedindo que o agente químico neurotóxico se ligue com essas enzimas protegidas. Assim, o agente químico só consegue se ligar à acetilcolinesterase que não está protegida pelo carbamato. $\mathrm{O}$ agente químico neurotóxico que não se liga à acetilcolinesterase é hidrolisado de forma relativamente rápida na corrente sanguínea, enquanto a acetilcolinesterase que está protegida pelo carbamato é espontaneamente descarbomilada. A piridostigmina então é hidrolisada, liberando a acetilcolinesterase para voltar a sua ação de hidrolisar a acetilcolina (Scott 2007). 
O grande problema deste tipo de pré-tratamento é que, apesar de ajudar na prevenção da morte do indivíduo exposto, ele não impede que a performance funcional da pessoa exposta seja afetada, bem como não impede que haja incapacidade comportamental, perda de consciência ou, até mesmo, dano permanente no cérebro, uma vez que, devido à estrutura quaternária deste medicamento, a piridostigmina dificilmente conseguirá cruzar a barreira hematoencefálica em circunstancias normais (Scott 2007).

Por fim, é importante destacar que de nada adiantará o pré-tratamento com este carbamato se o indivíduo exposto ao agente químico neurotóxico não receber o tratamento adequado posterior à contaminação, com atropina, oxima e, eventualmente, diazepan. A piridostigmina, por si só, não é capaz de oferecer um tratamento eficaz: ela auxilia, somente, na sobrevida do indivíduo exposto para que este tenha um tempo maior de chegar a um centro médico ou receber o tratamento adequado em campo (Scott 2007; Saxena et al. 2008).

Este pré-tratamento é importantíssimo se existir a possibilidade do indivíduo ser contaminado com Soman, uma vez que o aging da enzima acetilcolinesterase ocasionado por este agente químico é muito rápido. Uma vez que isto ocorre, a oxima não consegue mais atuar no organismo para voltar à produção da acetilcolinesterase. A piridostigmina neste caso, atuaria aumentando a sobrevida da enzima e retardando o seu processo de aging.

Na Guerra do Golfo, ocorrida no início da década de 1990, os militares dos Estados Unidos da América utilizaram o brometo de piridostigmina como pré-tratamento para uma eventual exposição ao Soman. Apesar da sua utilização no supracitado conflito, foi somente em 2003 que o brometo de piridostigmina foi aprovado pelo governo dos Estados Unidos da América para ser utilizado como pré-tratamento por militares (Pereira et al. 2008).

Por fim, é importante mencionar que vários especialistas vinculam o brometo de piridostigmina como um dos possíveis fatores responsáveis por causar a Síndrome da Guerra do Golfo, a qual acometeu mais de 250.000 militares. Dentre os principais sintomas da mencionada síndrome, podemos citar: fadiga, dor de cabeça, insônia, problemas respiratórios, lapsos de memória, tonturas e indigestão.

\section{Butirilcolinesterase (Bioscavengers — "biolimpadores")}

Existem duas categorias de bioscavengers: a estequiométrica, que são proteínas produzidas naturalmente pelo corpo humano, como, por exemplo, colinesterase (ChE) e carboxilesterase (CaE), que se ligam e reagem com o agente neurotóxico; e a catalisadora, que causa a quebra da molécula 
do agente químico neurotóxico, regenera-se e repete este processo até todo o agente químico ser destruído (Lenz et al. 2008).

Alguns requisitos são importantes para uma substância ser considerada apta a atuar como bioscavenger: deve ocasionar o menor ou nenhum efeito colateral comportamental ou psicológico, deve fornecer proteção para uma exposição equivalente a uma concentração considerada 5 vezes maior que a $\mathrm{LD}_{50}$ de um ou mais agentes neurotóxicos, deve permanecer entre $11 \mathrm{e}$ 15 dias na corrente sanguínea e deve ser biologicamente inerte caso o organismo não seja exposto ao agente químico neurotóxico (Lenz et al. 2008; Ross et al. 2008).

Ao compararmos qual das duas categorias de bioscavengers seria a mais adequada, verificamos que a categoria estequiométrica, apesar de ser bastante eficiente, tem um ponto negativo, qual seja, cada molécula de proteína deste tipo de bioscavenger tem a capacidade de se ligar a somente uma molécula de agente químico neurotóxico. Assim, a capacidade de proteção está proporcionalmente ligada à concentração de agente químico na corrente sanguínea, o que faz com que seja necessária uma grande quantidade deste tipo de bioscavenger, uma vez que o peso das moléculas desta categoria de bioscavenger é alto (podendo chegar a $80.000 \mathrm{Da}$ ), diferente do peso molecular médio de um agente neurotóxico, que é extremamente baixo (180 Da) (Lenz et al. 2008).

Já a vantagem do bioscavenger catalisador é que, apesar de possuir o mesmo peso molecular da categoria estequiométrica, é necessária apenas uma pequena quantidade de proteínas da categoria catalisadora para proteger um indivíduo exposto a uma alta concentração de agente químico neurotóxico. Outra vantagem é que, pelo fato da proteína não ser consumida no processo de desintoxicação, como ocorre na categoria estequiométrica, o bioscavenger catalisador permanece disponível para proteger contra múltiplas exposições de doses grandes ou pequenas (Lenz et al. 2008).

Cabe destacar que o provável bioscavenger que será escolhido para ser utilizado (butirilcolinesterase) é de origem humana, o que reduz bastante a probabilidade de eles serem reconhecidos pelas células do sistema imunológico como uma ameaça, podendo permanecer, assim, por um período mais longo na circulação sanguínea. Outra vantagem de serem de origem humana é o fato de que os indivíduos estariam protegidos por uma substância que o próprio corpo humano já produz, ao invés de drogas injetadas estranhas ao corpo humano que podem ocasionar efeitos colaterais (Lenz et al. 2008). 


\section{CONCLUSÃO}

É de suma importância que pesquisas de tratamentos mais eficazes contra a exposição dos agentes neurotóxicos continuem sendo realizadas como forma de possuirmos uma resposta cada vez mais rápida a este tipo de agressão, e que não deixem sequelas nos indivíduos expostos. Apesar de alguns países terem ainda estocado este tipo de arma química, a grande preocupação recai sobre as organizações terroristas, que hoje em dia possuem conhecimento e mecanismos de fabricarem tais agentes.

Um ataque terrorista utilizando esta classe de agentes químicos certamente pode provocar uma grande quantidade de mortos e feridos, principalmente se for utilizado um método de dispersão eficiente e um agente químico com um grau de pureza adequado. Fechar os olhos para esta ameaça é ser negligente com uma possibilidade não muito remota, uma vez que a internet e a globalização fazem com que a facilidade para se adquirir esta arma devastadora se torne cada vez mais acessível.

As Forças Armadas, bem como os órgãos envolvidos na segurança pública, devem possuir meios eficazes e devem estar preparados tecnicamente para responderem a um eventual ataque com estas substancias, quer seja na forma de arma química propriamente dita, quer seja na forma de utilização de pesticidas, que podem ocasionar os mesmos riscos à saúde humana, dependendo do tipo de pesticida e concentração utilizada.

Por fim, é importante enfatizar a principal diferença da intoxicação ocasionada pelos agentes químicos neurotóxicos e por inseticidas organofosforados. Enquanto os agentes químicos neurotóxicos geralmente possuem uma alta solubilidade na gordura, os inseticidas organofosforados geralmente possuem baixa solubilidade (Pulley and Jones 2008).

Assim, na hipótese de intoxicação ocasionada por inseticida, a reserva de gordura corporal pode favorecer a permanência deste por mais tempo no interior do corpo humano, uma vez que ele irá se prender na gordura e não irá se dissolver com facilidade. Desta forma, a concentração de inseticida no sangue pode atingir doses que causem toxidade aguda durante vários dias, podendo gerar convulsões neste período (Pulley and Jones 2008).

Já no caso de exposição ao agente químico neurotóxico, o quadro descrito acima geralmente não ocorre, uma vez que ele possui alta solubilidade na gordura, e isso faz com que ele seja diluído mais rapidamente. Como resultado, a concentração desta substância no sangue só consegue atingir um nível crítico na intoxicação inicial, ou seja, apenas uma vez (Pulley and Jones 2008). 


\section{REFERÊNCIAS}

Aas, P., T. A. Veiteberg, and F. Fonnum. 1987. Acute and sub-acute inhalation of an organophosphate induce alteration of cholinergic muscarinic receptors. Biochem Pharmacol., [S. l. $]$, v. 36 (8), p. 1261-6.

Ballough, G. et al. 2008. "Chapter 6: Neuroprotection as a treatment for nerve agent survivors”. In: Tuorinsky, S. D. (Org.). Medical Aspects of Chemical Warfare. Washington: Borden Institute, 22 1-242.

Ganesan, K., S. K. Raza, and R. Vijayaraghavan. 2010. “Chemical warfare agents”. Journal of Pharmacy \& BioAllied Sciences, [S.l.] (set.): 166-178. https://www.ncbi. nlm.nih.gov/pmc/articles/PMC3148621.

Grob, D. and Harvey, J. C. 1958. Effects in mano f the anticholinesterase compound Sarin (isopropyl methyl phosphonofluoridate). J. Clin. Invest. 37(1): 350-368.

Hilmas, C. J., J. K. Smart, and B. Hill. 2008. “Chapter 5: Nerve Agents”. In. Sidell, F.R., J. Newmark, and J. H. Mcdonough. Medical Aspects of Chemical Warfare. Washington, DC: Borden Institute.

Hoeing, Steven L. 2007. Compendium of chemical warfare agents. Nova Iorque: Springer.

Jimmerson V. R, Shih, T. M and Mailman. 1989. "Variability in soman toxicity in the rat: Correlation with biochemical and behavioral measures". Toxicology 57, $\mathrm{n}$ 3: 241-254.

Lallement, G., Carpenteir, P., Pernot-Marino, I., Baubichon, D., Collet, A., Blanchet, G. 1991a. Involvement of the diferente rat hippocampal glutamatergic receptors in development of seizures induced by soman. Neurotoxicology 4: 655-664.

Lenz, D. E. et al. 2008. "Chapter 8: Nerve agent bioscavangers: Progress in development of a new mode of protection against organophosphorus exposure”. In: Romano Jr., James A., B. J. Lukey, and H. Salem, (Org.). Chemical Warfare Agents: Chemistry, Pharmacology, Toxicology, and Therapeutics. Florida: CRC Press, 175-202.

Mcdonough, J. H., and James A. Romano Jr. 2008. "Chapter 4: Health effects of low-level exposure to nerve agents”. In: Romano Jr., James A., B. J. Lukey, and H. Salem (Org.). Chemical Warfare Agents: Chemistry, Pharmacology, Toxicology, and Therapeutics. Florida: CRC Press, 71-96.

Mors, L. Feijão de Calabar e Trombeta: A utilização de plantas em julgamentos. 2018. https://oetnobotanico.wordpress.com/2015/06/17/feijao-de-calabar-e-trombeta-a-utilizacao-de-plantas-em-julgamentos. 
Thavaselvam, D. and Flora, Swaran S. 2014. "Chemical and Biological Warfare Agents”. In: Gupta, Ramesh C (Org). Biomarkers in Toxicology. Hopkinsville: Academic Press, 521-538.

Oppenheimer Torres, Felipe. 2018. "A Convenção de Paris e a sua temerária interpretação para a utilização de armas químicas". Revista Brasileira Militar de Ciências, Goiânia, 4, no. 10 (nov.): 16-22 http://rbmc.org.br/edicao-atual/revista-brasileira-militar-de-ciencias-vol-4-no-10-novembro-de-2018.html.

Pereira, Edna F. R. et al. 2008. "Chapter 10: Novel medical countermeasure for oganophosphorus intoxication: connection to Alzheimer's disease and dementia”. In: Romano Jr., James A., B. J. Lukey, and H. Salem (Org.). Chemical Warfare Agents: Chemistry, Pharmacology, Toxicology, and Therapeutics. Florida: CRC Press, 219-232.

Pitschmann, Vladimir. 2014. "Overall View of Chemical and Biochemical Weapons". Toxins, [S.l.] (jun.): 1761-1784, https://www.researchgate.net/publication/262927085_Overall_View_of_Chemical_and_Biochemical_Weapons

Pulley, Stephen A, and Michael R. Jones, 2008. "Chapter 24: Emergency medical response to a chemical terrorist attack”. In: Romano Jr., James A., B. J. Lukey, and H. Salem (Org.). Chemical Warfare Agents: Chemistry, Pharmacology, Toxicology, and Therapeutics. Florida: CRC Press, 675-711.

Rao, K.S., Y. Aracava, D. L. Rickett, and E. X. Albuquerque. 1987. Noncompetitive blockade of the nicotinic acetylcholine receptor-ion channel complex by an irreversible cholinesterase inhibitor. J Pharmacol Exp Ther., [S. l.], v. 240 (1), p. $337-44$.

Ross, M. C. et al. 2008. "Chapter 7: Nerve agent bioscavenger: Development of a new approach to protect against organophosphorus exposure". In: Tuorinsky, S. D. (Org.). Medical Aspects of Chemical Warfare. Washington: Borden Institute, 243-258.

Salem, H., Andrew L. Ternay Jr., and J. K. Smart. 2008. "Chapter 1: Brief history and use of chemical warfare agents in warfare and terrorism". In: Romano Jr., James A., B. J. Lukey, and H. Salem (Org.). Chemical Warfare Agents: Chemistry, Pharmacology, Toxicology, and Therapeutics. Florida: CRC Press, 1-20.

Saxena, A. et al. 2008. "Chapter 7: Novel approaches to medical protection against chemical warfare nerve agents". In: Romano Jr., James A., B. J. Lukey, and H. Salem (Org.). Chemical Warfare Agents: Chemistry, Pharmacology, Toxicology, and Therapeutics. Florida: CRC Press, 146-174. 
Scott, L. 2007. "Chapter 17: Pretreatment for nerve agent poisoning". In: Marrs, T. C., R. L. Maynard, and F. R. Sidell (Org.). Chemical Warfare Agents: Toxicology and Treatment. 2. ed. West Sussex: John Wiley \& Sons Ltd, 343-354.

Sidell, F. R., J. Newmark, and J. H. Mcdonough. 2008. "Chapter 5: Nerve Agent". In: Tuorinsky, S. D. (Org.). Medical Aspects of Chemical Warfare. Washington: Borden Institute, 155-217.

Silva, G. R. et al. 2012. "Defesa química: Histórico, classificação dos agentes de guerra e ação dos neurotóxicos”. Química Nova, [S.l.], 35, no. 10, 2083-2091.

Tucker, J. B. 2006. War of nerves: Chemical warfare from World War I to AlQaeda. Nova Iorque: Anchor Books.

Watson, A.; D. Opresko, R. Young, V. Hauschild, J. King, and K. Bakshi. 2009. "Chapter 6: Organophosphate Nerve Agents". In: Gupta, Ramesh C. Handbook Toxicology of chemical warfare agents. San Diego: Academic Press, 43-67.

Wetherell, A. and G. Mathers. 2007. "Chapter 6. Respiratory Protection". In: Marrs, T. C., R. L. Maynard, and F. R. Sidell (Org.). Chemical Warfare Agents: Toxicology and Treatment. 2. ed. West Sussex: John Wiley \& Sons Ltd, 157-173. 


\section{NOTAS}

1. Até hoje não se sabe ao certo qual agente químico foi utilizado, uma vez que há divergências se foi utilizado Sarin ou algum agente da série "V".

2. Esta foi a primeira vez na História que os neurotóxicos foram utilizados em um campo de batalha.

3. Processo de inativação irreversível causado pela ligação covalente dos organofosforados à serina do sítio ativo das colinesterases. 


\section{RESUMO}

O presente artigo tem como objetivo explorar a temática referente à classe dos agentes químicos neurotóxicos. Ao longo deste artigo, será abordado o aspecto histórico dos agentes neurotóxicos, peculiaridades das armas químicas binárias, propriedades físicas e químicas dos agentes neurotóxicos, mecanismos de ação, toxicidades, efeitos diretos no sistema nervoso, ligação com colinesterases sanguíneas e pré-tratamentos. No presente trabalho, será explorada ainda a possibilidade da utilização de agentes químicos neurotóxicos por organizações terroristas, bem como será demonstrada a preocupação que as autoridades governamentais devem possuir com os pesticidas, uma vez que estas substâncias podem ocasionar efeitos fisiológicos bastante semelhantes aos ocasionados pelos agentes neurotóxicos.

Palavras-chave: Agentes neurotóxicos; Arma química binária; Novichok; Terrorismo.

\section{ABSTRACT}

The aim of this paper is to explore the class of neurotoxic chemical agents. This paper will discuss the historical aspect of neurotoxic agents, peculiarities of binary chemical weapons, physical and chemical properties of neurotoxic agents, mechanisms of action, toxicities, direct effects on the nervous system, binding to blood cholinesterases and pre-treatments. This paper will also explore the possibility of the use of neurotoxic chemical agents by terrorist organizations, as well as demonstrate the concern that government authorities should have with pesticides, since these substances can cause physiological effects very similar to those caused by neurotoxic agents.

Keywords: Neurotoxic chemical agents; Binary chemical weapons; Novichok; Terrorism. 
